\title{
A COMUNICAÇÃO VERDE FALA POR SI? EFEITOS NA IDENTIDADE CORPORATIVA E PROPENSÃO DE COMPRA
}

\author{
1- Simone Alves Pacheco de Campos \\ Doutoranda em Administração pela Universidade Federal do Rio Grande do Sul (UFRGS), Brasil \\ simoneapcampos@gmail.com \\ http://lattes.cnpq.br/2403565845137368
}

\section{2- Lisiane Celia Palma}

Doutoranda em Administração pela Universidade Federal do Rio Grande do Sul (UFRGS), Brasil Professora do Instituto Federal de Educação, Ciência e Tecnologia (IFRS), Brasil. lisiane.palma@yahoo.com.br http://lattes.cnpq.br/2069164928850530

\section{3- Daiane Mulling Neutzling}

Doutoranda em Administração pela Universidade Federal do Rio Grande do Sul (UFRGS), Brasil daineutzling@gmail.com http://lattes.cnpq.br/5914874079788560

\section{4- Luis Carlos Zucatto}

Doutoranda em Administração pela Universidade Federal do Rio Grande do Sul (UFRGS), Brasil luiszucatto@yahoo.com http://lattes.cnpq.br/9128987043195154

\section{5- Luis Antonio Slongo}

Doutor em Administração pela Universidade de São Paulo (USP), Brasil. Professor do Programa de Pós-Graduação em Administração da Universidade Federal do Rio Grande do Sul (UFRGS), Brasil. laslongo@ea.ufrgs.br http://lattes.cnpq.br/1902788698931900

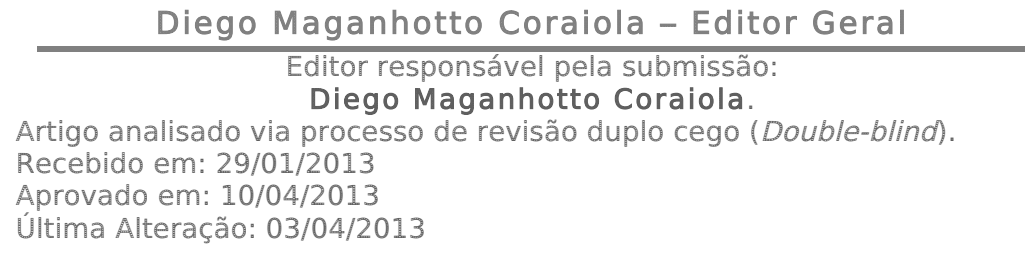

* Contato Principal: Rua Venâncio Aires, 2165. Passo da Areia, Santa Maria - RS, Brasil. CEP: 97020-620. 


\section{A COMUNICAÇÃO VERDE FALA POR SI? EFEITOS NA IDENTIDADE CORPORATIVA E PROPENSÃO DE COMPRA}

\section{RESUMO}

A temática da sustentabilidade tem alterado o cenário estratégico das empresas diante de várias mudanças. Uma destas diz respeito às transformações nos critérios de decisão dos consumidores, que começam a predispor-se a tornar o verde a sua prioridade, atraídos por marcas que possuem princípios verdes. A partir disso, as empresas passaram a usar estratégias de comunicação dos seus princípios sustentáveis diretamente nas embalagens de seus produtos. Diante disso, o objetivo deste estudo foi verificar os impactos da comunicação verde na identidade corporativa e propensão de compra. Para tanto, realizou-se um estudo de caráter quase-experimental e com design fatorial da ordem de 2 (Embalagens e Selos Verdes) x 2 (Identidade Corporativa e Propensão de Compra), manipulando a presença ou ausência do tipo de apelo utilizado (embalagem ou selos verdes). Como principais resultados, o estudo mostra que a identidade corporativa é percebida positivamente mediante a presença tanto dos selos quanto pelas embalagens verdes - sendo os primeiros mais efetivos - o que também influencia, de maneira positiva, na propensão de compra.

Palavras-chave: Comunicação verde, Propensão de compra, Identidade corporativa.

\section{DOES THE GREEN COMMUNICATION TALK BY ITSELF? EFFECTS IN CORPORATE IDENTITY AND PURCHASE PROPENSITY}

\section{ABSTRACT}

The sustainability issues have changed the strategic environment of companies facing many changes. One of these being related to changes in the consumer's decision criteria that have begun to promising the green being acted to brands that have linked green principles. Since that the companies started to use communication strategies for their sustainable principles directly on the packaging of their products. Thus, the objective of this study was to verify the impact of green communication on corporate identity and propensity to purchase. Therefore, we carried out a quasi-experimental study and with the factorial design of the order 2 (Packaging and Green Stamps) $\times 2$ (Corporate Identity and Willingness to Purchase), manipulating the presence or absence of the type of appeal used (packaging or green stamps). As the main results of the study shows that corporate identity is perceived positively by both, the presence of seals for packaging as green - the former being more effective - which also affects, in a positive way, the propensity to buy.

Keywords: Green communication, Propensity to purchase, Corporate identity. 


\section{Introdução}

A temática da sustentabilidade tem alterado o cenário estratégico das empresas diante de novas regulações, maior volume de informações disponíveis, expectativas da sociedade, mas principalmente, mudanças em alguns critérios de decisão dos consumidores (Ottman, 1994; Gurau e Ranchhod, 2005). Neste aspecto, Grant (2008) afirma que existem consumidores que estão dispostos a tornar o verde a sua prioridade, sendo atraídos por marcas que possuem princípios verdes e que oferecem um significado ou uma vantagem "eco" nos seus produtos, de uma forma fidedigna.

Pela perspectiva das empresas, o comportamento em relação aos impactos ambientais passou a determinar, ao mesmo tempo, uma restrição de mercado e um fator estratégico. Atualmente, atrelar uma imagem ética e socioambientalmente responsável à marca pode criar um efeito positivo no valor de mercado e uma vantagem competitiva devido aos menores riscos percebidos pelos investidores, além de boa aceitação dos consumidores (Ottman, 1994; Bacallan, 2000; Aligleri, Aligleri e Kruglianskas, 2009).

Desta forma, surge a necessidade das empresas desenvolverem uma identidade corporativa associada à ética ambiental e estratégias visando à comunicação de práticas ambientalmente corretas. Para tanto, existem diversas formas de comunicação, efetivando-se por meio de apelos com informações nas embalagens e rótulos de ações genéricas até informações de mudanças de determinados componentes usados na fabricação dos produtos, o que traz dificuldades para a empresa - na escolha de qual é a forma mais efetiva de comunicação e para o consumidor - que, muitas vezes, é "bombardeado" por um excesso de informações sem saber quais são verdadeiras e quais visam apenas a ampliar as vendas de determinado produto.

Ao avaliar os instrumentos de comunicação usados pelo marketing ambiental, observa-se que a utilização de expressões que identificam produtos ecologicamente corretos, pode, muitas vezes, ter o efeito contrário nos consumidores ao gerar mais dúvidas do que esclarecimentos. A utilização de expressões que identificam um produto como verde ou ambientalmente correto em rótulos, embalagens ou publicidade, pode ocasionar problemas em relação ao significado dos termos e, principalmente, em relação à veracidade das informações. Contudo, há também aquelas informações que são mais reconhecidas e respeitadas pelos consumidores, como é o caso das certificadas pelos selos verdes. Neste caso, o consumidor é auxiliado na identificação de produtos verdes pelo aval de organizações que concedem selos e garantem a idoneidade pela sua independência em relação aos interesses da indústria.

Em relação ao consumo de produtos verdes ou ambientais, outro fator importante a ser considerado, e que tem sido retratado na literatura, é o gap existente entre consciência ambiental versus hábitos de consumo. Ainda que exista um nível de preocupação e conhecimento sobre estes produtos, em muitos casos, isso não necessariamente reflete na escolha e compra destes produtos (Gupta e Ogden, 2009; Gifford, Scannell, Kormos, Smolova, Biel, Boncu, e Hine, 2009).

Assim, torna-se interessante verificar se realmente os consumidores reconhecem as informações apresentadas nas embalagens (seja através de selos verdes ou de outros apelos ambientais contidos nas mesmas), bem como se a presença ou ausência destas informações fazem-nos relacionar o produto a uma empresa preocupada com as questões socioambientais e, ao mesmo tempo, aumenta a propensão de compra destes consumidores.

A partir deste contexto, este estudo busca investigar os impactos da comunicação verde na identidade corporativa e na propensão de compra. Para tanto, foram definidos os seguintes objetivos específicos: (i) analisar a influência das ações de marketing verde, em relação aos apelos ambientais e selos ambientais presentes nas embalagens na observação da identidade corporativa; (ii) analisar como as ações de marketing verde, em relação aos apelos ambientais e selos ambientais presentes nas embalagens influenciam na propensão de compra dos consumidores.

Este artigo encontra-se dividido em cinco seções, além desta introdução. Na sequência, realiza-se uma breve revisão da literatura sobre identidade corporativa e comunicação verde. Logo após, são apresentados os procedimentos metodológicos, os resultados da pesquisa e as considerações finais. Por fim, são expostas as referências bibliográficas utilizadas.

\section{Identidade Corporativa}

Cientes de que uma identidade corporativa sólida apresenta ampla gama de potenciais benefícios aumento da confiança e lealdade à marca, atração de profissionais de alta qualidade, adição de valor para seus produtos similares, aumento da motivação dos empregados (Olins, 2003; Van Riel e Balmer, 1997), pesquisadores e profissionais de marketing procuram, de forma consistente, inserir nas suas agendas preocupações relativas a essa questão (Christensen e Askegaard, 2001).

Para Olins (2003), a companhia consegue projetar uma perspectiva de que possui identidade forte quando evidencia uma percepção clara de seu negócio, de si própria, de como quer ser percebida por seus diferentes públicos. Neste sentido, uma identidade forte pode contribuir para a companhia diferenciar-se, caso seus produtos ou serviços tendam a se "comoditizar" (Almeida e Nunes, 2007). 
Identidade corporativa é a soma de todas as formas pelas quais uma companhia procura identificar-se a seus diversos públicos - comunidade, consumidores, empregados, imprensa, atuais e futuros acionistas, analistas de seguros e bancos de investimentos. A identidade corporativa é, então, a soma de símbolos e artefatos concebidos para comunicar o ideal de autopercepção da organização a seus públicos (Margulies, 1977; Christensen e Askegaard, 2001).

Na lógica de Biloslavo e Trnavecvic (2009), a identidade corporativa é influenciada por aspectos como o compromisso da alta gestão da companhia, resultados alcançados e posição da companhia em seu ambiente competitivo, comportamento interno e externo, conteúdo e forma como se comunica com seus diferentes públicos.

Uma das questões emergentes no que diz respeito à identidade corporativa é suas estratégias em relação às temáticas ambientais (Ahearne, Bhattacharya, e Gruen, 2005). Neste sentido, Frandsen e Johansen (2011) defendem que a adoção de práticas que visem a minimizar os impactos ambientais das atividades das empresas, desde a extração da matéria prima, transportes, embalagens, até a disposição final dos produtos após seu de ciclo de vida, podem gerar efeitos positivos sobre a identidade corporativa.

No que concerne à propensão de compra, estudos (Van Riel e Balmer, 1997; Brown e Dacin, 1997; Davies, Chun, da Silva e Roper, 2001; Sheth, Mittal e Newmann, 2001; Battacharya e Sen, 2004) sugerem que se as ações socioambientais que as empresas/organizações desenvolvem forem consistentes, essas empresas/organizações fidelizam mais facilmente os consumidores que suas concorrentes

\section{Comunicação Verde}

As estratégias competitivas relacionadas à reputação e valorização da marca, segundo Peattie e Charter (2003), necessitam adequar-se às novas necessidades dos consumidores, sobretudo, ao novo "zeitgeist social", ou seja, um novo momento social que passa a valorizar a sustentabilidade nas mais variadas esferas da sociedade.

O desenvolvimento de processos e produtos mais sustentáveis e a necessidade de divulgar estas ações a fim de obter o reconhecimento dos consumidores fez surgir uma nova orientação para o marketing, mais precisamente o chamado marketing verde, definido como “a gestão holística de processos, responsável por identificar, antecipar e satisfazer as necessidades dos consumidores e sociedade, de uma maneira lucrativa e sustentável" (Peattie e Charter, 2003, p. 727).

A valorização dos produtos ecológicos fez com que o marketing atuasse diretamente na apresentação dos produtos de modo a atender as necessidades de sustentabilidade dos consumidores. Um dos mecanismos utilizados é a comunicação visual, apresentada na forma de embalagens com apelos ecológicos integrados às propagandas que visam a comunicar uma identidade pró-ambiental ou de uma empresa "eco-amigável" perante o mercado (Grillo, Tokarczyk e Hansen, 2008).

As propagandas e os apelos ecológicos são os veículos efetivos de comunicação das estratégias ambientais das empresas e podem ser apresentados em novos designs de embalagens feitas a partir de materiais reciclados ou biodegradáveis, em embalagens com redução de componentes, em produtos concentrados e até mesmo na forma de refis (Banerjee, Gulas, e Iyer, 1995). Segundo Leonidou, Leonidou, Palihawadana e Hultman (2011), diante do aumento da preocupação pública pelas questões ecológicas e pela demanda de produtos eco-amigáveis, as propagandas ambientais cresceram exponencialmente nas últimas décadas, tornando-se uma das forças condutoras do consumo de produtos ecológicos. Ainda que existam problemas de "greenwashing" - ou seja, o uso indevido do marketing por certas empresas ao comunicar que seus produtos possuem características ecológicas quando, na verdade, não o fazem -, a necessidade de transparência das empresas e o nível de informação dos consumidores faz com que haja um investimento, cada vez maior, nas formas de divulgação destes produtos de forma responsável.

São cada vez maiores os investimentos em estratégias de comunicação ambiental diante dos resultados positivos criados para as empresas, principalmente no que tange à melhoria de identidade e construção da reputação organizacional perante o mercado consumidor e seus stakeholders (Banerjee, Gulas e Iyer, 1995; Mathur e Mathur, 2000; Puppim, 2005; Machado Filho, 2006; Ottman, 2011). Adotar práticas de responsabilidade ambiental acrescenta valor à marca ou nome da empresa, gera reflexos positivos em sua avaliação e melhora a reputação da mesma (Machado Filho, 2006). As empresas visam a serem vistas como éticas, não só no trato com seus colaboradores, mas também por suas ações voltadas aos mais diversos stakeholders. Através desta estratégia, procuram criar um "escudo" para proteger-se e tornarem-se invulneráveis, mostrando que se alinham às normas de seu tempo (Oliveira, Daher e Oliveira, 2006). Desta forma, a empresa que consegue adotar tais práticas melhor habilita-se na fidelização de clientes e na atração de investimentos, acesso a recursos externos e transações internacionais (Lodi, 2000).

Além da valorização da identidade, as propagandas ambientais aplicadas a rótulos e embalagens podem também afetar as atitudes e comportamento do consumidor, logo, sua propensão de compra (Pereira e Ayrosa, 2004; Blackwell, Miniard e Engel, 2005). Associações negativas à responsabilidade ambiental das empresas podem levar a um detrimento na avaliação dos produtos ou serviços, enquanto associações positivas podem melhorar esta avaliação (Brown e Dacin, 1997). 
Segundo Chatterjee (2009), os consumidores têm a pretensão de buscar alternativas por compras de produtos ambientalmente amigáveis quando comparam os impactos ambientais que estes causam. Já Hartmann, Ibáñez e Sainz (2005) afirmam que um fator significante para a mudança no comportamento de compra e a propensão dos consumidores em comprar produtos ambientalmente amigáveis está relacionada aos benefícios emocionais que lhes são importantes e que são enaltecidos por marcas e produtos que possuem preocupações socioambientais. A partir das discussões teóricas desenvolvidas anteriormente, emergem as seguintes hipóteses:

\section{H1: A utilização de apelos ambientais na forma de embalagens verdes influencia a identidade corporativa. \\ H2: A utilização de apelos ambientais na forma de embalagens verdes influencia positivamente na propensão de compra}

Além dos apelos ambientais na forma de propagandas, as empresas têm como alternativa o uso de selos ambientais ou selos verdes. Estes se referem à descrição de características e desempenho ambiental de um produto (Giridhar, 1998), possuindo a função de informar e, ao mesmo tempo, comprovar aos consumidores, por meio de uma instituição idônea, que as informações de ações ambientais contidas nos produtos são verdadeiras (Rocha e Queiroz, 2011).

Os selos ambientais podem ser autodenominados ou determinados por instituições terceiras. Os selos que são autodeclarados são colocados em um produto pelo fabricante, varejista ou comerciante e podem ser feitos sob a avaliação de um único atributo ou de uma avaliação geral do produto. Já os selos declarados por terceiros baseiam-se na conformidade com critérios pré-determinados que são verificados de forma independente por uma entidade competente externa (Rashid, Jusoff e Kassim, 2009). As empresas que buscam estas certificações seguem um padrão de especificações exclusivas para um produto ou um processo e, após sofrerem uma avaliação externa, tornam-se aptas a usar os selos nas suas embalagens. O uso de selos verdes tem se tornado frequente dado o poder de legitimidade criado frente aos consumidores. De acordo com Teisl, Roe e Hick (2002), os consumidores respondem positivamente aos selos verdes, contribuindo para o marked share destes produtos junto às empresas.

Ao aplicar um estudo em quatro diferentes países sobre a importância dos selos verdes, Thogersen (2002) revelou que a grande maioria dos consumidores presta atenção, pelos menos, algumas vezes, aos selos ambientais. Outra pesquisa realizada pelo Instituo Akatu e Faber-Castell no Brasil, cujo objetivo era compreender melhor as motivações do consumidor ao adotar práticas ou assimilar valores relativos ao consumo consciente, também traz resultados interessantes. A referida pesquisa foi realizada em 2006 e envolveu a população urbana de todo o País - 1275 casos em 11 capitais/regiões metropolitanas - das classes A, B e C/D, com idade de 18 a 74 anos, aplicadas cotas e ponderações para estas variáveis e também para as variáveis de escolaridade, estado civil e sexo. Destaca-se, como um dos resultados de tal pesquisa, as respostas dos entrevistados sobre a possibilidade de pagar mais por produtos que apresentem selo comprobatório de nãoagressão ao meio ambiente. O resultado é que $37 \%$ (quase quatro em cada dez consumidores) declararam estarem dispostos a pagar mais por produtos que não agridam o meio ambiente, desde que houvesse neles um selo comprovando esta informação (Belinky, Echegaray, Mattar, Rodrigues e Velho, 2007).

Portanto, os selos verdes são considerados uma maneira de conquistar credibilidade e identidade positiva por parte das empresas diante das reivindicações ambientais dos consumidores (Ottman, 2011). Além disso, são também tidos como instrumentos com um alto potencial de atuação não somente em relação ao fornecimento de informações aos consumidores, mas também de influência sobre as decisões de compra e de captação da preferência de mercado destes consumidores (Instituto Akatu, 2008; Rashid, Jusoff e Kassim, 2009; Ottman, 2011). Diante da discussão da importância dos selos verdes perante o comportamento dos consumidores e os resultados que poderão ser gerados para as empresas, formularam-se as seguintes hipóteses:

\section{H3: A presença de selos verdes nas embalagens influencia positivamente a identidade corporativa.}

H4: A presença de selos verdes nas embalagens influencia positivamente na propensão de compra.

\section{Método e Procedimentos}

Com intuito de compreender se as ações de marketing verde influenciam a observação de identidade e propensão de compra realizou-se uma pesquisa de natureza quasi-experimental. Neste sentido, a pesquisa tem caráter conclusivo e baseia-se em condições de causalidade entre os constructos. Assim, o presente estudo encontra-se embasado no pressuposto de variação concomitante entre as variáveis (Malhotra, 2006), ou seja, a inclusão de apelos ambientais influencia positivamente a identidade corporativa e na propensão de compra.

A pesquisa empregou um estudo fatorial, tendo em vista que se desejou medir os efeitos de duas ou mais variáveis independentes em vários níveis (Malhotra, 2006). Assim, o estudo fatorial realizado caracteriza-se por ser de ordem 2 (Embalagens e Selos Verdes) x 2 (Identidade Corporativa e Propensão de Compra). Desta forma, foram realizados dois estudos, empregando o mesmo design fatorial, modificando a presença ou ausência do 
tipo de apelo utilizado (embalagem ou selos verdes), uma vez que se buscou compreender quais desses apelos oferecem melhor explicação acerca da identidade corporativa e da propensão de compra. A Figura 1 (um) demonstra o modelo de pesquisa utilizado no presente estudo.

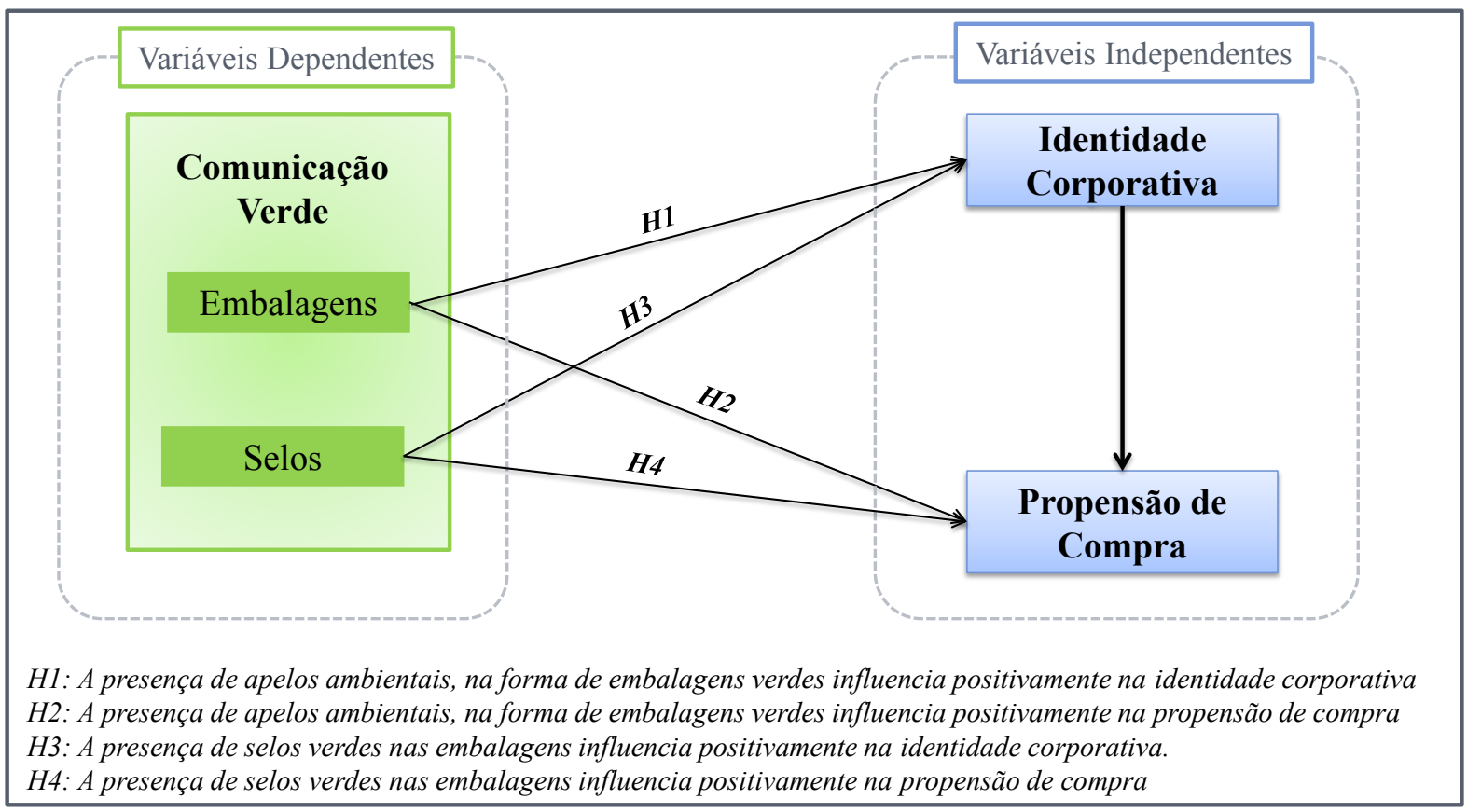

Figura 1 - Modelo de pesquisa utilizado no estudo

Fonte: Elaborado pelos autores

Para a realização deste estudo, os sujeitos experimentais foram abordados em locais de grande circulação em Porto Alegre, Rio Grande do Sul. Foram feitas demonstrações aos consumidores de embalagens de produtos de higiene e limpeza doméstica (sabão em pó). A escolha por este produto justifica-se devido ao fato deste ser utilizado pela maioria da população e ser um produto que tem impacto ambiental considerável. Para os indivíduos que aceitaram participar do experimento, primeiramente, foram feitas duas questões de triagem da amostra que buscavam saber se aquela pessoa compra e utiliza habitualmente o produto que estava sendo apresentado. Logo após, para as pessoas cujas respostas fossem positivas, foram lidas instruções gerais aos sujeitos experimentais, explicando como proceder ao experimento. As informações fornecidas visavam a enfatizar que os sujeitos deveriam responder às perguntas de acordo com sua livre opinião, bem como foi entregue uma régua de medição, em que podia ser visualizada a escala adotada. Ainda, forneceram-se informações acerca da boa qualidade do produto e do preço do mesmo, o qual se estimou em torno do valor médio cobrado no mercado por produtos da mesma categoria. Este procedimento foi realizado a fim de garantir a padronização das informações aos sujeitos experimentais.

Cada um dos estudos foi conduzido da seguinte forma: Estudo 1 - foi entregue aos sujeitos experimentais uma embalagem de sabão em pó, sendo esta criada para o experimento, destacando a presença de selos verdes ("FSC"1 e "reciclável"), a fim de constatar a influência dos mesmos na identidade corporativa como ambientalmente responsável e na propensão de compra; Estudo 2 - foi entregue aos sujeitos experimentais uma embalagem de sabão em pó, que foi criada para o estudo, destacando-se o material da embalagem (papel reciclável) e a presença da propaganda ("linha eco"), com o objetivo de verificar a influência das embalagens na percepção de identidade de empresa como ambientalmente responsável e propensão de compra. As manipulações foram checadas na observação após os estímulos, através de questionamentos feitos aos sujeitos visando a testar as hipóteses do estudo.

Para confrontar os dois estudos, foi realizado o Estudo 3, sendo este referente ao grupo de controle que seguiu os mesmos procedimentos dos anteriores, contudo, neste caso, foi apresentada uma terceira embalagem criada para o experimento, também com marca inexistente, que não continha nenhum tipo de apelo verde ou selo verde. As manipulações foram checadas na observação após os estímulos, através de questionamentos feitos aos sujeitos visando a testar as hipóteses do estudo. Para ambos os estudos, o grupo de controle seguiu os mesmos procedimentos, contudo, neste caso, foi apresentada uma terceira embalagem criada para o experimento, também com marca inexistente, que não continha nenhum tipo de apelo verde. É importante ressaltar que, como variável de controle, foi utilizada uma marca fictícia - denominada Easy Clean criada exclusivamente para o estudo, para minimizar a possível influência do conhecimento prévio do consumidor. Na Figura 2 (dois), são demonstradas as imagens das embalagens utilizadas nos estudos descritos. Após o experimento, realizou-se um debriefing, informando aos sujeitos experimentais quais eram os objetivos do experimento e como foram realizadas as manipulações (Malhotra, 2006).

Desta forma, foram pesquisadas 180 pessoas, sendo 60 entrevistados para cada um dos grupos. Em todos os estudos, as impressões dos sujeitos experimentais foram mensuradas através de um questionário 
estruturado em torno de duas escalas. Para a avaliação da identidade corporativa, utilizou-se a escala adaptada do estudo de Ahearne, Bhattacharya e Gruen (2005), composta por quatro itens. A segunda escala, referente à propensão de compra, foi adaptada do estudo de Baker e Churchill (1977), composta por três itens. Os constructos foram mensurados através de escalas do tipo de Likert de cinco pontos. Convém ressaltar que foi realizado um pré-teste do instrumento de pesquisa, visando a uma melhor adaptação deste ao contexto estudado, além de verificar se as questões eram compreensíveis aos pesquisados. Além disso, durante o préteste, questionou-se aos entrevistados quais eram suas impressões acerca da embalagem recebida, a fim de verificar se seriam necessárias modificações na arte das embalagens. Para a análise dos resultados, utilizou-se o software Statistical Package for Social Sciences (SPSS 17.0), no qual foram realizados os testes de média, desvio padrão, mediana, análise fatorial, coeficiente Alpha de Cronbach e análise de variâncias, tratados detalhadamente na seção de resultados.

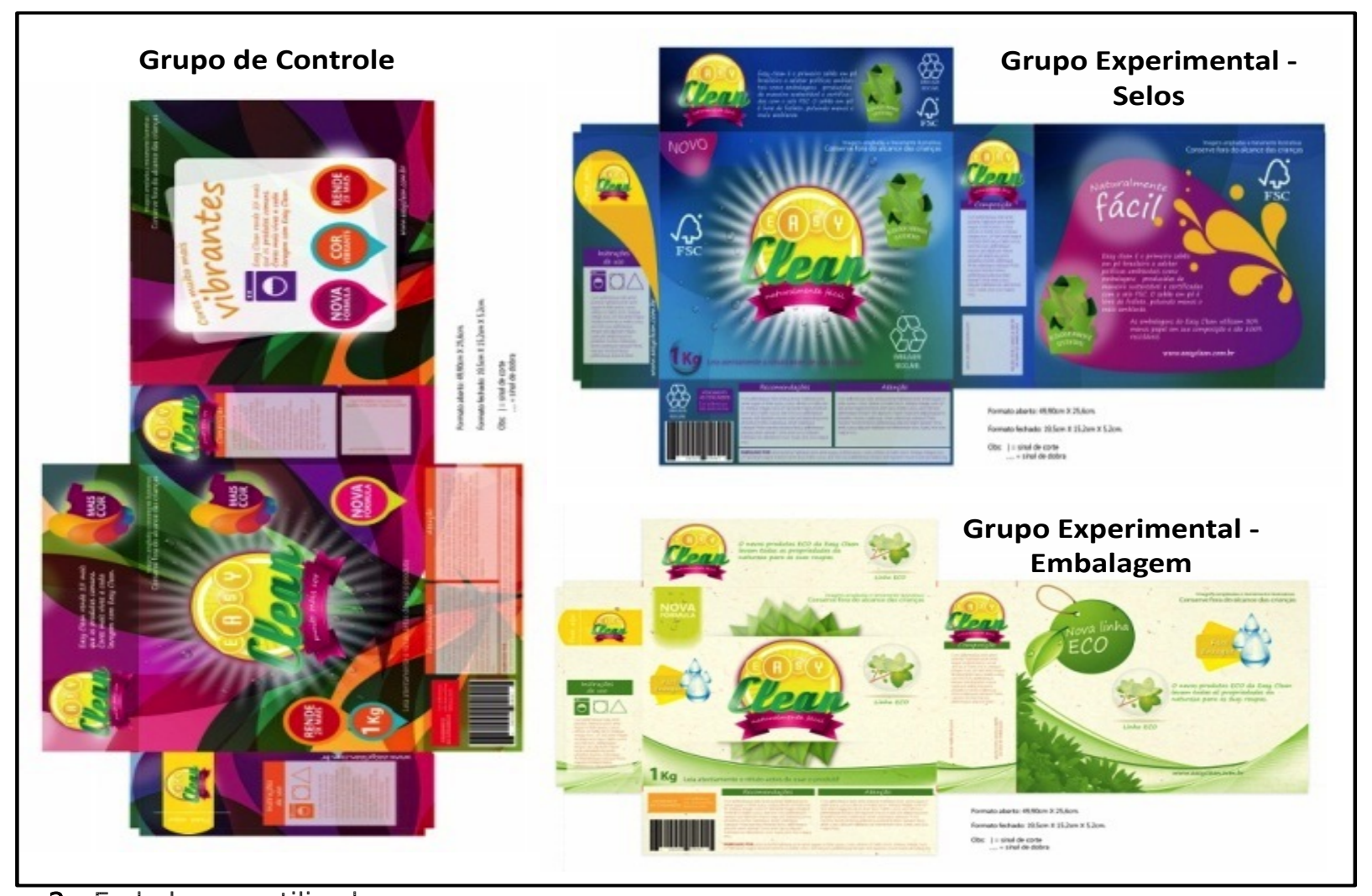

Figura 2 - Embalagens utilizadas

Fonte: Elaborado pelos autores

\section{Análise e Discussão dos Resultados}

Anterior à análise dos dados referentes aos testes de hipóteses, faz-se necessário uma breve descrição do perfil da amostra que compôs os três estudos, tomando-a de um modo geral. Quanto ao gênero, 34\% dos respondentes pertencem ao gênero masculino e $66 \%$ ao gênero feminino. A média de idade dos respondentes é de aproximadamente 36 anos. Em relação ao grau de escolaridade, a maioria dos pesquisados (26,52\%) possui ensino superior completo. No que tange à frequência de compras, a maior parte dos respondentes compra o produto uma vez por mês $(38,12 \%)$, seguidos de $31,5 \%$ que compram quinzenalmente. Ressalta-se que apenas $4,42 \%$ compram mais de uma vez por semana.

\subsection{Efeitos da Comunicação Verde na Identidade Corporativa}

Com o objetivo de compreender a influência dos apelos ambientais na percepção de identidade corporativa, utilizou-se a escala de Ahearne e Bhattacharya (2005), a qual contempla quatro itens, adaptada ao contexto brasileiro. Realizou-se a análise fatorial de componentes principais com normalização kaizer e rotação varimax. Convém ressaltar que os resultados obtidos para as medidas de adequação da amostra confirmaram a fatorabilidade dos dados. A referida análise resultou em uma estrutura unifatorial, confirmando o proposto por Ahearne, Bhattacharya e Gruen (2005), e obteve índices de Alpha de Cronbach que corroboram a validade do instrumento de coleta de dados $(\alpha=0,822)$.

Tendo em vista que o foco deste estudo residiu sobre a questão ambiental, ainda questiona-se aos pesquisados se os mesmos, com base na embalagem, percebiam a responsabilidade ambiental da empresa e identificavam-na como ambientalmente correta. A inclusão dessa variável ao construto de identidade 
corporativa justifica-se dado a atualidade e relevância do tema, bem como por mostrar-se adequada aos objetivos desta pesquisa.

A fim de verificar as diferenças entre os grupos em decorrência da presença ou a ausência de determinado argumento ecológico, realizou-se a análise de variância (ANOVA). Como pode ser visualizado na Tabela 1 (um), o teste mostrou-se significativo para as variáveis utilizadas, levando à rejeição da hipótese de igualdade de médias entre os grupos. Assim, considerando um nível de significância de 95\%, observa-se que existem diferenças significativas entre as médias dos grupos de controle e experimentais, no que se refere à identidade corporativa e percepção das ações de responsabilidade ambiental.

\begin{tabular}{l|l|c|c|c|c}
\hline \multicolumn{2}{c|}{ ANOVA } & $\begin{array}{c}\text { Soma dos } \\
\text { Quadrados }\end{array}$ & $\begin{array}{c}\text { Média dos } \\
\text { Quadrados }\end{array}$ & F & Sig \\
\hline \multirow{2}{*}{$\begin{array}{l}\text { Ações de Responsabilidade } \\
\text { Ambiental }\end{array}$} & Entre os grupos & 35,859 & 17,929 & \multirow{2}{*}{24,302} & \multirow{2}{*}{0,000} \\
\cline { 1 - 5 } Identidade Corporativa & Dentro dos grupos & 130,586 & 0,738 & \multirow{2}{*}{4,149} & \multirow{2}{*}{0,017} \\
\cline { 2 - 4 } & Entre os grupos & 3,509 & 1,754 & 0,423 & \\
\cline { 2 - 4 }
\end{tabular}

Tabela 1 - Teste ANOVA para Identidade Corporativa

Fonte: dados da pesquisa

A fim de conhecer o comportamento das variáveis estudadas dentro de cada um dos três grupos (Controle, Experimental Selos e Experimental Embalagens), calcularam-se as médias e os desvios-padrão das variáveis, conforme pode ser visto na Tabela 2 (dois).

\begin{tabular}{|c|c|c|c|c|c|}
\hline Variável & Grupo & Média & Desvio & $F$ & Sig \\
\hline \multirow{4}{*}{$\begin{array}{c}\text { Ações de Responsabilidade } \\
\text { Ambiental }\end{array}$} & Controle & 2,95 & 1,007 & \multirow{4}{*}{24,302} & \multirow{4}{*}{0,000} \\
\hline & Embalagem & 3,73 & 0,778 & & \\
\hline & Selo & 4,00 & 0,766 & & \\
\hline & Total & 3,56 & 0,964 & & \\
\hline \multirow{4}{*}{ Identidade Corporativa } & Controle & 2,94 & 0,65879 & \multirow{4}{*}{4,149} & \multirow{4}{*}{,017 } \\
\hline & Embalagem & 3,03 & 0,56778 & & \\
\hline & Selo & 3,27 & 0,71426 & & \\
\hline & Total & 3,08 & 0,66176 & & \\
\hline
\end{tabular}

Tabela 2 - Médias, desvios-padrão e significância das variáveis analisadas

Fonte: dados da pesquisa

A análise dos desvios-padrão mostra que, de certa forma, os pesquisados foram coerentes entre si, uma vez que foram obtidos, para a maioria das variáveis, baixos valores de desvio-padrão (Hair, Babin, Money and Samouel, 2005). O maior valor obtido residiu no grupo de controle, no qual se observa uma maior variabilidade nas respostas dos pesquisados. Em relação às médias, de uma forma geral, percebe-se que os sujeitos pesquisados avaliaram melhor a empresa quando o produto recebido continha apelo ecológico, uma vez que as médias atribuídas à identidade, em ambos os grupos experimentais, foram superiores às médias atribuídas ao grupo de controle.

Para compreender o comportamento das variáveis em cada um dos grupos, a análise de variância ( $p \leq$ 0,05 ) e o teste de Tukey HSD foram realizados para a comparação das médias, ao analisar-se o comportamento das variáveis dentro de cada grupo (Pestana e Gageiro, 2003). A realização deste teste visou a testar as hipóteses $\mathrm{H} 2$ e $\mathrm{H} 4$, em relação à percepção de identidade corporativa quando apresentado diferentes argumentos ecológicos. Os resultados encontram-se expostos na Tabela 3 (três).

Assim, os resultados obtidos demonstram que, apenas para o grupo experimental dos selos, obteve-se diferenças significativas, sendo que a média do grupo experimental foi superior à media do grupo de controle $\left(\mathrm{M}_{\text {controle }}=2,94<\right.$ Media $_{\text {ExSelo }}=3,27$; sig $\left.=0,00\right)$. Embora a média obtida atribuída ao grupo "Selos" para a Identidade corporativa ser um valor próximo ao ponto médio da escala, uma vez que a mediana dessa variável resultou em 4 (quatro), pode-se afirmar que os selos são vinculados positivamente à identidade corporativa.

\begin{tabular}{|c|c|c|c|c|}
\hline Variável Dependente & $\begin{array}{r}\text { Compa } \\
\text { Média }\end{array}$ & $\begin{array}{l}\text { ão entre as } \\
\text { os Grupos }\end{array}$ & $\begin{array}{c}\text { Diferenças de } \\
\text { Médias }\end{array}$ & Sig \\
\hline \multirow{2}{*}{ Ações de Responsabilidade Ambiental } & \multirow[t]{2}{*}{ Contole } & Embalagem & $-0,783$ & 0,000 \\
\hline & & Selo & $-1,049$ & 0,000 \\
\hline \multirow{2}{*}{ Identidade Corporativa } & Controle & Embalagem & $-0,089$ & 0,736 \\
\hline & & Selo & $-0,331$ & 0,016 \\
\hline
\end{tabular}

Tabela 3 - comparações entre as médias dos grupos e diferenças de médias

Fonte: Dados da Pesquisa

Este resultado remete ao entendimento de que os selos estão associados positivamente à formação de identidade corporativa, a qual está relacionada à soma de símbolos e artefatos concebidos para comunicar o ideal de autopercepção da organização (Margulies, 1977; Christensen e Askegaard, 2001). Pomering e Johnson 
(2009) acrescentam que, ao relacionar questões ambientais e sociais às formas de publicidade, a empresa passa aos seus mais diversos públicos a identidade de uma empresa socioambientalmente responsável ou, pelo menos, a promessa de que está agindo de acordo com preocupações sociais ou ambientais nos seus negócios. A identidade percebida pelos consumidores pode implicar decisões destes em relação a seus produtos ou serviços, tendo em vista que pressupõe a forma como esta empresa conduz suas ações. Os selos ambientais atestam que a empresa possui boas práticas em relação ao meio ambiente, demonstrando, ao menos, uma preocupação por parte da mesma quanto ao tema. Estes selos mostraram-se eficientes na comunicação com o público externo, haja vista que tiveram um impacto positivo na percepção dos entrevistados em relação à identidade corporativa.

No que se refere à compreensão em relação às ações de responsabilidade ambiental da empresa, identificando esta como ambientalmente responsável, os resultados mostraram-se significativos para ambos as ações de comunicação verde (grupo embalagens e grupo dos selos) quando comparados ao grupo de controle. Este resultado indica que tanto as embalagens quanto os selos foram associados pelos consumidores à identidade de empresa ambientalmente correta.

As embalagens com apelos ecológicos visam a comunicar a identidade pró-ambiental ou de uma empresa "eco-amigável" perante o mercado (Grillo, Tokarczyk e Hansen, 2008). Neste estudo, a embalagem contendo a informação "linha eco" foi associada à identificação de uma empresa ambientalmente correta e desenvolvedora de ações ambientais. Os resultados do estudo permitem afirmar que os consumidores avaliarão melhor as empresas que estejam associadas às questões ambientais nas quais acreditam.

Entretanto, observa-se que a diferença de médias entre o grupo de controle e o grupo dos selos é superior do que quando se compara o grupo de controle ao grupo no qual o argumento ecológico utilizado foram as embalagens $\left(M_{\text {controle }}=2,95\right.$; Media ${ }_{\text {ExSelo }}=4,00 ;$ Media ${ }_{\text {ExEmb }}=3,73 ;$ sig $\left.=0,00\right)$, sendo que as médias obtidas para o grupo exposto à presença dos selos foram superiores. Estes resultados indicam que a presença dos selos nas embalagens leva à percepção de identidade de empresa como ambientalmente correta, corroborando o que afirma Ottman (2011) com relação ao fato dos selos verdes serem considerados uma maneira de conquistar credibilidade e identidade positiva por parte das empresas diante das reivindicações ambientais dos consumidores.

Nessa mesma linha, estudos anteriores enfatizam que os selos trazem resultados positivos para as empresas principalmente no que tange à melhoria de identidade imagem e construção da reputação organizacional perante o mercado consumidor e seus stakeholders (Banerjee, Gulas e Iyer, 1995; Mathur e Mathur, 2000; Puppim, 2005; Machado Filho, 2006; Ottman, 2011). Como destacado por Machado Filho (2006), adotar práticas de responsabilidade ambiental acrescenta valor à marca ou nome da empresa, gera reflexos positivos em sua avaliação e melhora a reputação da mesma.

\subsection{Efeitos da Comunicação Verde na Propensão de Compra}

Para a investigação de aspectos relacionados à propensão de compra, utilizou-se a proposta de Baker e Churchill (1977). Após a análise fatorial exploratória, procedeu-se à realização da análise fatorial confirmatória, visando a confirmar a estrutura fatorial obtida no estudo original. Anterior à referida técnica, realizaram-se os testes de adequação da amostra os quais se mostraram significativos ( $\mathrm{KMO}=0,778$; Bartllet significativo a p< 0,001). A análise fatorial corroborou a estrutura unifatorial de Baker e Churchill (1977), bem como a confiabilidade do instrumento de pesquisa, uma vez que se obteve um índice de Alpha de Cronbach satisfatório $(\alpha=0,707)$. Após, foram realizados os testes de análise de variância a fim de identificar a existência de diferenças significativas entre os grupos submetidos às diferentes manipulações experimentais (selos, embalagens e grupo de controle). A Tabela 4 (quatro) mostra os resultados obtidos para a Análise de Variância (ANOVA) entre os grupos.

\begin{tabular}{l|l|r|r|c|c}
\hline \multicolumn{2}{c|}{ ANOVA } & $\begin{array}{c}\text { Soma dos } \\
\text { Quadrados }\end{array}$ & $\begin{array}{c}\text { Média dos } \\
\text { Quadrados }\end{array}$ & F & Sig \\
\hline \multirow{2}{*}{ Propensão de Compra } & Entre os grupos & 4,934 & 2,467 & \multirow{2}{*}{4,605} & \multirow{2}{*}{0,011} \\
\cline { 2 - 4 } & Dentro dos grupos & 94,806 & 0,536 & \multirow{2}{*}{4,605} \\
\hline
\end{tabular}

Tabela 4 - Teste ANOVA para Propensão de Compra

Fonte: Dados da Pesquisa

Através da análise dos dados constantes na Tabela 4 (quatro), observa-se que existem diferenças significativas entre as variâncias dos grupos no que tange à propensão de compra. Assim, os resultados demonstram que existem diferenças entre a presença de selos e embalagens verdes na propensão de compra. Para fins de análise, calcularam-se as médias e desvios-padrão para os grupos, conforme se pode visualizar na Tabela 5 (cinco).

Conforme os dados expostos na Tabela 5 (cinco), os valores de desvio-padrão obtido são todos inferiores a um, revelando baixos valores de desvio-padrão e demonstrando que os pesquisados foram coerentes entre si (Hair et al., 2005). O grupo no qual houve maior divergência entre as respostas dos pesquisados foi o grupo de controle, uma vez que revelou um maior valor de desvio-padrão. Ainda, observa-se que todas as médias obtidas residiram em torno de três, ou seja, do ponto médio da escala. 
Simone Alves Pacheco de Campos, Lisiane Celia Palma, Daiane Mulling Neutzling, Luis Carlos Zucatto, Luis Antonio Slongo

\begin{tabular}{c|l|c|c|c|c}
\hline \multicolumn{1}{c|}{ Variável } & \multicolumn{1}{|c|}{ Grupo } & Média & Desvio & F & Sig \\
\hline \multirow{3}{*}{ Propensão de Compra } & Controle & 3,174 & 0,761 & & \\
\cline { 2 - 5 } & Embalagem & 3,111 & 0,748 & \multirow{4}{*}{4,605} & \multirow{3}{*}{0,011} \\
\cline { 2 - 4 } & Selo & 3,491 & 0,681 & & \\
\cline { 2 - 4 } & Total & & & & \\
\hline
\end{tabular}

Tabela 5 - Médias e desvios-padrão para cada grupo

Fonte: dados da pesquisa

A fim de determinar as diferenças de médias no interior dos grupos, realizou-se a análise de variância, através do teste de Turkey (Pestana e Gageiro, 2003). Os resultados encontram-se dispostos na Tabela 6 (seis).

\begin{tabular}{c|l|l|l|l}
\hline Variável Dependente & \multicolumn{2}{|c|}{$\begin{array}{c}\text { Comparação entre as } \\
\text { Médias dos Grupos }\end{array}$} & $\begin{array}{c}\text { Diferenças } \\
\text { de Médias }\end{array}$ & \multicolumn{1}{c}{ Sig } \\
\hline \multirow{3}{*}{ Propensão de Compra } & \multirow{2}{*}{ Controle } & Embalagem & 0,0637 & 0,881 \\
\cline { 3 - 5 } & & Selo & $-0,3166$ & 0,039 \\
\cline { 2 - 5 } & \multirow{2}{*}{ Embalagem } & Controle & 0,0637 & 0,881 \\
\cline { 3 - 5 } & & Selo & $-0,38041$ & 0,014 \\
\hline
\end{tabular}

Tabela 6 - Comparação entre as médias dos grupos e diferenças de médias

Fonte: dados da pesquisa

Através da análise da Tabela 6 (seis), pode-se observar que, no grupo para o qual o apelo ecológico utilizado foi embalagem verde, não foram obtidos resultados significativos. Este resultado demonstra que as embalagens verdes não possuem impactos significativos na propensão de compra. Por outro lado, as diferenças entre as médias dos grupos mostraram-se significativas no grupo para o qual o apelo ecológico utilizado foi os selos. Neste grupo, as diferenças de médias mostraram-se estatisticamente superiores em relação ao grupo de controle $\left(M_{\text {controle }}=3,17 ; M_{\text {selo }}=3,49\right)$. Embora o resultado obtido seja um número próximo ao ponto neutro da escala, realizou-se análise da mediana e da frequência das respostas para esta variável, o que demonstrou que a maior parte das respostas residem em torno de 4 (quatro). Este resultado permite inferir que os selos verdes influenciam positivamente na propensão de compra. Ainda, pode-se notar que a diferença entre as médias atribuídas para o grupo experimental das embalagens e para o dos selos é significativa, demonstrando que a média dos selos é superior a médias das embalagens no que tange à propensão de compra.

Este resultado encontra-se alinhado aos resultados obtidos por Hansmann, Koellner e Scholz (2006) e Thompson, Anderson, Hansen, e Kahle (2010), que afirmam que a utilização de selos, que retratam certificações ambientais, podem guiar a intenção de compra, uma vez que atribui maior credibilidade à empresa. Diante do exposto, os selos podem ser caracterizados como instrumentos com um alto potencial de influência sobre as decisões de compra e de captação da preferência de mercado dos consumidores (Instituto Akatu, 2008; Rashid, Jusoff e Kassim, 2009; Ottman; 2011). O resultado ratifica ainda o que afirmam Teisl, Roe e Hicks (2002), que os consumidores respondem positivamente aos selos verdes contribuindo para o market share destes produtos junto às empresas.

\subsection{Efeitos da Comunicação Verde na Identidade e Propensão de Compra: Analisando os Efeitos de Selos e Embalagens de Forma Integrada}

Com vistas a compreender quais dos apelos ambientais pesquisados geram melhores resultados na identidade corporativa e propensão de compra, convém analisar os impactos de selos e embalagens de maneira integrada. Essa análise encontra-se consubstanciada na análise dos testes das hipóteses anteriormente definidas, tratados nas duas seções de resultados anteriores.

Em relação aos resultados obtidos para a identidade corporativa, pode-se observar que esta é influenciada positivamente mediante a presença tanto dos selos quanto das embalagens verdes, o que leva a não rejeitar Hipóteses 1 (um) e 3 (três). Entretanto, cabe salientar que, embora ambos os apelos sejam responsáveis por melhorias na identidade da marca e sua associação como "pró-ambiental", a associação com os selos verdes tem maior impacto na percepção de identidade corporativa, uma vez que as diferenças de médias foram estatisticamente superiores.

Por outro lado, os resultados demonstraram que a associação de empresa como “ambientalmente correta" é positiva para o grupo no qual o apelo utilizado foi o selo verde. Assim, de uma forma geral, visto que o grupo no qual o apelo ecológico utilizado foram os selos obteve médias estatisticamente superiores ao grupo de controle para as duas variáveis, pode-se inferir que a utilização de selos apresenta maior impacto na identidade corporativa do que a utilização do apelo ambiental nas embalagens.

No que se refere à propensão de compra, a análise dos resultados sinalizou que esta só foi influenciada pela presença de selos verdes como apelo, uma vez que as diferenças de médias obtidas, ao se comparar o grupo de controle com o grupo experimental no qual se utilizou embalagens como apelo, não foram significativas. Estes resultados, por um lado, levam à rejeição da Hipótese 2 (dois) e a não rejeição da Hipótese 4 (quatro). Assim sendo, pode-se inferir que os selos apresentam maior influência sobre a decisão de comprar ou não um produto. 
Através dos testes das hipóteses anteriores, pode-se admitir que os efeitos gerados pela presença dos selos são maiores em relação à identidade corporativa e propensão de compra do que os efeitos gerados pela presença das embalagens. A Figura 3 (três) mostra uma síntese dos resultados obtidos através dos testes de hipóteses.

\begin{tabular}{|c|l|c|c|}
\hline \multicolumn{1}{|c|}{ Hipótese } & Decisão \\
\hline 1 & $\begin{array}{l}\text { A utilização de apelos ambientais na forma de embalagens verdes influencia a identidade } \\
\text { corporativa }\end{array}$ & Não Rejeitar \\
\hline 2 & $\begin{array}{l}\text { A utilização de apelos ambientais na forma de embalagens verdes influencia } \\
\text { positivamente na propensão de compra }\end{array}$ & Rejeitada \\
\hline 3 & $\begin{array}{l}\text { A presença de selos verdes nas embalagens influencia positivamente a identidade } \\
\text { corporativa. }\end{array}$ & Não Rejeitar \\
\hline 4 & $\begin{array}{l}\text { A presença de selos verdes nas embalagens influencia positivamente na propensão de } \\
\text { compra. }\end{array}$ & Não Rejeitar \\
\hline
\end{tabular}

Figura 3 - Síntese dos resultados dos testes de hipóteses

Fonte: dados da pesquisa

Como visto, as propagandas e os apelos ecológicos são os veículos de comunicação das estratégias ambientais das empresas e podem ser apresentados, dentre outras formas, em embalagens feitas a partir de materiais reciclados ou por meio dos selos verdes, mostrando-se, no presente estudo, estes últimos mais efetivos. Uma possível explicação para tal resultado pode estar na questão de o produto apresentar, na sua embalagem, apelos como "linha eco", ou mesmo a embalagem ter sido feita com material reciclado, pouco informa aos consumidores sobre as reais ações da empresa em relação às questões ambientais.

Já os selos, quando declarados por terceiros, têm a vantagem de trazerem a credibilidade de uma organização externa que atesta que determinada empresa respeita e segue algumas normas ambientais, sejam elas relacionadas ao seu produto e/ou ao processo (Hansmann, Koellner e Scholz, 2006). Logo, os selos utilizados na embalagem do estudo 1 (um) trazem uma maior confiança do que aqueles declarados pela própria empresa (autodenominados), como o apelo "linha eco" existente na embalagem do estudo 2 (dois), ou mesmo o material utilizado na embalagem. Os resultados reafirmam o que assinalam Rashid, Jusoff e Kassim (2009) e Ottman (2011) em relação ao fato dos selos verdes serem considerados uma excelente maneira de conquistar credibilidade e identidicação por parte das empresas diante dos consumidores, além de que são instrumentos com um alto potencial de atuação no que concerne ao fornecimento de informações aos consumidores e de influência sobre as decisões de compra e de captação da preferência de mercado destes consumidores.

Outro possível motivo para os apelos utilizados na embalagem do estudo 2 (dois) terem tido menor impacto positivo nas respostas pode ter sido pelo fato destes, por serem autodenominados, levarem a possibilidade de serem relacionados ao "greenwashing", (Leonidou et al., 2011; Zaman, Miliutenko, e Nagapetan, 2010), o que pode ter ocasionado certa desconfiança por parte dos respondentes, que não demonstraram ter credibilidade em relação ao produto e seu fabricante somente pelo fato daquele ter a embalagem feita de material reciclável e a autodeclaração ser da linha eco. Dessa forma, observa-se que embalagens feitas a partir de materiais reciclados chamam atenção do consumidor, entretanto, nem todos relacionam tal fato diretamente com a identidade de empresa ambientalmente responsável.

\section{Considerações Finais}

Os temas relacionados à sustentabilidade, de modo geral, e às questões ambientais, em específico, têm assumido um papel de destaque, tanto no meio acadêmico quanto empresarial, na medida em que se, por um lado, os debates acadêmicos ressaltam a importância de estudos que visem a ampliar o conhecimento acerca do tema, por outro lado, tem-se o desenvolvimento de uma consciência crítica por parte do consumidor, que, agora, passa a exigir um comportamento social e ambientalmente responsável por parte das empresas.

Esta pesquisa buscou investigar o impacto da comunicação verde na identidade corporativa e propensão de compra. Em relação à identidade corporativa, percebe-se que tanto selos quanto embalagens geram impactos positivos na identidade corporativa, sendo que o estudo demonstrou que os selos apresentam influência maior na percepção de identidade corporativa. Da mesma forma, em relação à identificação de "empresa ecologicamente correta", os resultados mostraram-se favoráveis, tanto para os selos, quanto para as embalagens, sendo que os selos apresentaram-se mais efetivos.

Este resultado permite inferir que a presença dos selos faz com que os consumidores avaliem de forma diferenciada a identidade corporativa, atrelando esta à questão ambiental. Tendo em vista que tais resultados referem-se ao caso dos selos declarados por terceiros, os quais se baseiam no cumprimento de padrões e normas já estabelecidos, e que são verificados de forma independente por uma entidade competente externa (Rashid, Jusoff e Kassim, 2009), o impacto na identidade corporativa e o reconhecimento como empresa ambientalmente responsável revela o reconhecimento de uma prática organizacional efetiva. Assim, o fato de os consumidores valorizarem estes tipos de apelos ambientais pode sinalizar que eles estão mais críticos e conscientes em relação às ferramentas de comunicação verde utilizadas pelas empresas. 
No que tange à propensão de compra, os resultados indicaram que somente a presença dos selos está associada a um provável comportamento de compra por parte dos consumidores, indicando que, quando estão presentes, a propensão de compra é maior. No caso das embalagens com apelos ambientais, os resultados não foram significativos, apontando que a presença de uma embalagem "verde" nada diz acerca da intenção de compra do consumidor.

Analisando-se os resultados obtidos de forma integrada, observa-se que os selos levam tanto a uma melhor avaliação da identidade corporativa atrelada à questão ambiental, quanto aumentam a propensão de compra do produto. Assim, os selos demonstraram produzir resultados melhores nas duas variáveis analisadas. Consoante ao exposto, Zaman, Miliutenko e Nagapetan (2010) enfatizam que somente as informações do rótulo não garantem que a empresa desenvolva práticas efetivas de preservação ambiental.

Cabe ressaltar que o estudo foi feito apenas com um tipo de produto e com uma população específica, o que limita as extrapolações dos resultados. Entretanto, traz contribuições importantes, tanto para o meio acadêmico quanto empresarial, no que diz respeito aos impactos das propagandas e selos verdes na identidade corporativa e propensão de compra, demonstrando que a adoção de estratégias que contemplem ações voltadas às questões ambientais podem conferir vantagens competitivas às organizações. Sugere-se que estudos sejam feitos utilizando outros tipos de produtos e públicos diversos a fim de complementarem os resultados aqui apresentados.

\section{Notas}

1- O selo FSC, criado pelo Forest Stewarship Council, é um sistema de certificação florestal internacionalmente reconhecido, que identifica, através de sua logomarca, produtos originados do bom manejo florestal. A instituição define padrões universais para a emissão da certificação, bem como realiza o periodicamente o controle das organizações afilhadas (FSC, 2012).

\section{Referências}

Ahearne, M., Bhattacharya, C. B., \& Gruen, T. (2005). Antecedents and Consequences of Customer-Company Identification: Expanding the Role of Relationship Marketing. Journal of Applied Psychology, 90(3), 574.

Aligleri, L; Aligleri, L.A \& Kruglianskas, I. (2009). Gestão Socioambiental. São Paulo: Atlas

Almeida, A. L. C. \& Nunes, D. A. (2007). Mensagens corporativas e a construção de sentido sobre as organizações. Organicom. 7(1), p. 258-279.

Bacallan, J. J. (2000). Greening the supply chain. Business and Environment, 6(5), 11-12.

Baker, M. J. \& Churchill Jr, G. A. (1977). The impact of physically attractive models on advertising evaluations. journal of Marketing research, 538-555.

Banerjee, S., Gulas, C. S. \& Iyer, E. (1995). Shades of green: a multidimensional analysis of environmental advertising. Journal of Advertising, 21-31.

Battacharya, C. B. \& Sen, S. (2004). Doing better at doing good: when, why and how consumers respond to corporate social iniciatives? . California Management Review, 47(1), 10.

Belinky, A.; Echegaray, F.; Mattar, H.; Rodrigues, G. \& Velho, C. (2007) Como e por que os brasileiros praticam o consumo consciente? São Paulo: Instituto Akatu. 80 p.

Biloslavo, R. \& Trnavcevic, A. (2009). Web sites as tools of communication of a "green" company. Management Decision, 47(7), 1158-1173.

Blackwell, R. D.; Miniard, P. W. \& Engel, J. F. (2005) Comportamento do consumidor. São Paulo: Pioneira Thomson Learning

Brown, T.J., \& Dacin, P.A. (1997). The company and the product: corporate associations and consumer product responses. The Journal of Marketing, 61 (1) 68-84.

Chatterjee, Patrali (2009), “Green Brand Extension Strategy and Online Communities," Journal of Systems and Information Technology, 11 (4), 367-384.

Christensen, L.T., \& Askegaard, S. (2001). Corporate identity and corporate image revisited-A semiotic perspective. European journal of Marketing, 35(3/4), 292-315.

Davies, G., Chun, R., da Silva, R.V., \& Roper, S. (2001). The personification metaphor as a measurement approach for corporate reputation. Corporate Reputation Review, 4(2), 113-127.

Frandsen, F., \& Johansen, W. (2011). Rhetoric, Climate Change, and Corporate Identity Management. Management Communication Quarterly, 25(3), 511-530.

FSC - Forest Stewarship Council. Disponível em http://www.fsc.org/. Acesso em: 12 jan. 2012. 
Gifford, R., Scannell, L., Kormos, C., Smolova, L., Biel, A. Boncu, S., \&. Hine, D. (2009). Temporal pessimism and spatial optimism in environmental assessments: An 18-nation study. Journal of Environmental Psychology, 29(1), $1-12$

Giridhar, TR. (1998). Eco-labelling: A comparative analysis. Colourage, 45(6), 27-30.

Grant, J. (2008). Green marketing. Strategic Direction, 24(6), 25-27.

Grillo, N., Tokarczyk, J., \& Hansen, E. (2008). Green advertising developments in the US forest sector: A followup. Forest Products journal, 58(5), 40.

Gupta, S., \& Ogden, D.T. (2009). To buy or not to buy? A social dilemma perspective on green buying. Journal of Consumer Marketing, 26(6), 376-391.

Gurau, C., \& Ranchhod, A. (2005). International green marketing: A comparative study of British and Romanian firms. International Marketing Review, 22(5), 547-561.

Hair, J., Babin, B, Money, A. H, Samouel, P. (2005). Fundamentos de Métodos de Pesquisa em Administração. Porto Alegre: Bookman.

Hansmann, R., Koellner, T., \& Scholz, R.W. (2006). Influence of consumers' socioecological and economic orientations on preferences for wood products with sustainability labels. Forest Policy and Economics, 8(3), 239250.

Hartmann, P., Ibáñez, V.A., \& Sainz, F.J.F. (2005). Green branding effects on attitude: functional versus emotional positioning strategies. Marketing Intelligence \& Planning, 23(1), 9-29.

Instituto Akatu. (2008) Sumário Pesquisa 2006 e 2007 - RSE - Percepção do Consumidor Brasileiro. Disponível em: http://www.akatu.org.br/Publicacoes/Consumo-Consciente\#sthash.10o2ZLzk.dpuf. Acesso em: 12 jan. 2012.

Leonidou, L.C., Leonidou, C.N., Palihawadana, D., \& Hultman, M. (2011). Evaluating the green advertising practices of international firms: a trend analysis. International Marketing Review, 28(1), 6-33.

Lodi, J. B (2000). Governança corporativa: o governo da empresa e o Conselho de Administração. Rio de Janeiro: Campus.

Machado Filho, C. P. (2006). Responsabilidade social e governança: o debate e as implicações. São Paulo: Thomson Learning.

Malhotra, N. K. (2006). Pesquisa de Marketing: uma orientação aplicada (4a ed.). Porto Alegre: Bookman. Margulies, W. P. (1977). Make the most of your corporate identity. Harvard Business Review, 55(4), 66-74. Mathur, L.K. \& Mathur, I. (2000). An analysis of the wealth effects of green marketing strategies. Journal of Business Research, 50(2), 193-200.

Olins, W. (2003). Corporate identity: the myth and the reality. In.: Balmer, J. M. T.; Greiser, S. A. Revealing the corporation: perspectives on identity, image, reputation, corporate branding and corporate-level marketing. London: Routledge.

Oliveira, M. C.; Daher, W. M.; \& Oliveira, B. C. (2006). Responsabilidade social corporativa e geração de valor reputacional: estudo de multicaso, segundo o modelo de Hopkins, de empresas do setor energético do nordeste brasileiro. Paper preseted in VI Congresso Usp de Controladoria e Contabilidade, São Paulo.

Ottman, J. A. (2011). The new rules of Green Marketing. San Francisco: Berrett-Koehler Publishers.

Ottman, J. A. (1994) Marketing Verde: desafios e Oportunidades para a nova era do Marketing. São Paulo: Makron Books.

Peattie, K.; \& Charter, M. (2003). Green marketing. In: Baker, M.; Hart, S. The marketing book. Ed. Butter wealth. Pereira, S. J. N.; \& Ayrosa, E. A. T. (2004) Atitudes relativas a marcas e argumentos ecológicos: um estudo experimental. Revista Eletrônica de Gestão Organizacional. 2 (2) p. 134-145.

Pestana, M. H. \& Gageiro, J. N. (2003). Análise de dados para ciências sociais: a complementaridade do SPSS (3 ed.). Lisboa: Sílabo.

Pomering, A. \& Johnson, L. W. (2009). Advertising corporate social responsibility initiatives to communicate corporate image: Inhibiting scepticism to enhance persuasion. Corporate Communications: An International Journal, 14(4), 420-439.

Puppim, J. A (2005). O. Uma avaliação dos balanços sociais das 500 maiores. RAE Eletrônica. 4 (1) p. 1-20

Rashid, A. N.R.N.; Jusoff, K; \& Kassim, K.M. (2009). Eco-Labeling Perspectives amongst Malaysian Consumers. Canadian Social Science, 5(2), 1-10. 
Rocha, A. L. P ; \& Queiroz, J. P. (2011) Um estudo sobre o peso do selo orgânico no processo decisório de compra de consumidores de mate e sucos prontos no Rio de Janeiro. Paper presented at the XIII ENGEMA, São Paulo.

Sheth, J. N.; Mittal, B. \& Newman, B. I. (2001) Comportamento do cliente: indo além do comportamento do consumidor. São Paulo: Atlas.

Teisl, M.F., Roe, B., \& Hicks, R.L. (2002). Can eco-labels tune a market? Evidence from dolphin-safe labeling. Journal of Environmental Economics and Management, 43(3), 339-359.

Thogersen, J. (2002). Promoting green consumer behavior with eco-labels. New tools for environmental protection: Education, information, and voluntary measures, 83-104.

Thompson, D.W., Anderson, R.C., Hansen, E.N., \& Kahle, L.R. (2010). Green segmentation and environmental certification: insights from forest products. Business Strategy and the Environment, 19(5), 319-334.

Van Riel, C.B.M., \& Balmer, J.M.T. (1997). Corporate identity: the concept, its measurement and management. European journal of Marketing, 31(5/6), 340-355.

Zaman, A. U., Miliutenko, S., \& Nagapetan, V. (2010). Green marketing or green wash?: A comparative study of consumers' behavior on selected Eco and Fair trade labeling in Sweden. Journal of Ecology and the Natural Environment, 2(6), 104-111. 